\title{
Exploratory study estimating the impact of performance-based financing (PBF) on quality of care and on the contextual factors mediating the effectiveness of PBF in improving quality of care in Zimbabwe
}

\author{
Ronald U. Mutasa ${ }^{1,2} \wedge$, Sarah Baird ${ }^{2}$, Felicia Takavarasha ${ }^{1}$, Anne Markus ${ }^{2}$, Jed Friedman ${ }^{1}$, Wu Zeng ${ }^{3}$ \\ ${ }^{1}$ The World Bank, Washington, DC, USA; ${ }^{2}$ The George Washington University, Milken Institute School of Public Health, Washington, DC, USA; \\ ${ }^{3}$ Department of International Health, Georgetown University, Washington, DC, USA \\ Contributions: (I) Conception and design: J Friedman, S Baird, RU Mutasa, W Zeng, A Markus; (II) Administrative support: F Takavarasha; (III) \\ Provision of study material or patients: J Friedman, RU Mutasa; (IV) Collection and assembly of data: J Friedman, RU Mutasa, F Takavarasha; (V) \\ Data analysis and interpretation: All authors; (VI) Manuscript writing: All authors; (VII) Final approval of manuscript: All authors. \\ Correspondence to: Ronald U. Mutasa. The World Bank, 1818 H Street, Washington DC, 20433, USA. Email: rmutasa@worldbank.org.
}

\begin{abstract}
Background: Ensuring value for health sector spending is a universal concern for policy makers in lowand middle-income countries (LMICs), where health care demands are rising and health sector financing is limited. Performance-based financing (PBF) is more frequently being implemented in LMICs to improve quality of care and ultimately health system outcomes. Through PBF, LMICs can potentially reduce variation in clinical practice, because PBF provider incentives are directly linked to achievement of predefined quality of care standards and adherence to quality protocols. Zimbabwe implemented PBF in 16 districts as a health system reform to improve the quality and coverage of health services from 2011. This paper first estimates the impact of PBF on quality of care, and then explores contextual factors mediating the effectiveness of PBF in improving quality of care in Zimbabwe.
\end{abstract}

Methods: The World Bank collected household and health facility data in 2010/2011 and 2014 (baseline and end line years, respectively). Thirty-two districts served as the total study sample for the impact evaluation, comprising $16 \mathrm{PBF}$ pilot districts and 16 comparison districts. These 32 districts were purposively sampled out of Zimbabwe's 64 districts and then pair-matched on the basis of observable information described below. The pair-matching process sought to improve the power of inference and provide balance on observable district and facility characteristics. Two datasets were merged and then analyzed, one with household information and the other with health facility and health worker information. Pairing of households with health facilities was done at the community level. Baseline imbalances were adjusted for by difference-in-difference (DID) regression analysis. Contextual factors were analyzed to determine the most influential factors. Quality of care was measured for antenatal care (ANC), extended program on immunization (EPI), institutional deliveries, curative care, and postnatal care (PNC) services. A composite quality of care index was created using these five health services.

Results: Overall, PBF was found to have no effect on quality of care for services, except for institutional deliveries. PBF improved quality of institutional delivery by 0.01 percentage points. Results of individual contextual factors on their impact of PBF on quality of care were varied. An increase in the distance between health facilities and communities decreased the impact of PBF on quality of care by about $1.21 \%(\mathrm{P}=0.0020)$, while distance from the district capital had no impact on PBF effects on quality of care. The size of the catchment area, mean population wealth, and availability of skilled health workers had no impact on PBF effects on quality of care. However, health workers' job satisfaction increased the impact of PBF on quality of

\footnotetext{
$\wedge$ ORCID: 0000-0002-0332-3169.
} 
care by $27.7 \%(\mathrm{P}<0.0001)$.

Conclusions: Evaluations of complex health system reform interventions such as PBF need to go beyond exploring effects on priority health outcomes. As a strategic purchasing tool, PBF design should be informed by a country's contextual factors. At the same time, evidence on contextual factors outside the control of policy makers and the health system—such as mean population wealth-must be better understood and documented.

Keywords: Result-based financing; performance-based financing (PBF); low- and middle-income countries (LMICs); contextual factor; quality of care

Received: 25 April 2020; Accepted: 06 November 2020; Published: 25 June 2021.

doi: 10.21037/jhmhp-20-60

View this article at: http://dx.doi.org/10.21037/jhmhp-20-60

\section{Introduction}

Ensuring value for health sector spending is a universal concern for policy makers in low- and middle-income countries (LMICs), where health care demands are rising and health sector financing is limited. In the context of implementing strategies and interventions to achieve Universal Health Coverage (UHC) and ultimately Sustainable Development Goals (SDGs) by 2030, value for health sector spending is critical. For LMICs to achieve the third health $\mathrm{SDG}^{1}$, improved access to high quality health care is imperative (1).

An array of concepts and definitions constitute quality of health care. The two most prominent are: (I) the Donabedian framework of structure, process, and outcome quality; and (II) the Institute of Medicine's (IOM) six dimensions of quality (IOM Board on Health Care Services, 2001). While Donabedian defines quality of care as the final output of processes and structures within health care delivery systems (Das et al., 2016), the IOM's definition of quality in health care is linked to the extent to which health outcomes in a population are consistent with professional knowledge of health care standards (2).

To improve health care quality, and at the same time achieve value for money in health financing, high income countries and LMICs have initiated various reforms, including health insurance, prepayment schemes, and provider payment mechanisms (3). Performance-based incentives for health involve cash or nonmonetary payments or rewards transferred to a national or subnational government, manager, provider, payer, or consumer of health services after predefined results have been attained and verified (4). Performance-based incentives encompass various forms of incentives for health systems and households; LMICs and Organization for Economic Cooperation and Development (OECD) countries are turning to this approach to improve health system performance (5). At least 34 performance-based incentive hospital schemes were active in 14 OECD countries in 2017, and between 2004 and 2015, and at least 30 LMICs were at various stages of piloting and scaling up performance-based incentive schemes (4).

The underlying rationale is that performance-based financing (PBF) can extrinsically motivate health providers through incentives. By financially rewarding improvements in quality of health care, health providers will make greater efforts to achieve better results (3). As such, PBF is a core component of strategic purchasing of health services in a growing number of LMICs. Strategic purchasing helps link resources for health to the effective delivery of quality services (6).

Through PBF, LMICs can potentially reduce variation in clinical practice because provider incentives are directly linked to the achievement of predefined quality of care standards and adherence to set protocols (7). $\mathrm{PBF}$ programs can provide direct incentives for quality, or through payment formulas that combine quantity and quality indicators that determine payments made to

\footnotetext{
${ }^{1}$ This SDG (Ensure healthy lives and promote wellbeing for all at all ages) addresses all major health priorities, including: reproductive, maternal, and child health; communicable, non-communicable, and environmental diseases; universal health coverage; and access for all to safe, effective, quality and affordable medicines and vaccines.
} 
health providers $(1,8)$. In addition to financial incentives, $\mathrm{PBF}$ programs combine financial incentives with quality assurance and increased health provider supervision (4). Payments from PBF programs increase or decrease based on regularly aggregated scores (i.e., monthly, quarterly, or bi-annually) from a quality of care checklist agreed upon in advance by stakeholders.

Evidence on the effects of PBF on quality of health care in LMICs is limited, but growing. Evaluations in Rwanda, Argentina, Cambodia, Tanzania, and Zambia illustrate PBF's potential for improving coverage and quality of health services (9-13). Yet in some LMIC settings, PBF has demonstrated mixed results.

Given that PBF is a complex health systems reform intervention, it is essential to understand not only PBF's effects on outcomes, but also underlying contextual factors that might blunt or amplify the effectiveness of PBF on quality of health care outcomes in LMIC settings.

To date, there is no empirical evidence on effects of contextual factors on PBF's impact on quality of care $(9,14,15)$. Program performance on quality of care may be influenced by many factors. These factors include population characteristics, such as population mean education or wealth. Existing evidence has shown that access to life-saving maternity health services can be hindered by the cost of accessing health services and the willingness of the population to access these services. In 2012, Sila et al. found that among rural women in South Africa, household wealth, geographic location, and staff attitudes were major determining factors in women delivering in health facilities (16). Distance to health facilities deterred women from seeking maternity services; women who stayed furthest from health facilities were least likely to deliver in health facilities. A similar finding in Kenya found that distance to health facilities and socio-economic status significantly influenced women's decisions on institutional deliveries (17).

Availability of maternal health services is determined by availability of skilled staff to deliver these services. However, improved staff attitudes towards clients also improve quality of health services, which in turn increases acceptability and use of these services. Women who experience negative staff attitudes are less likely to use health services. Health workers who are not satisfied with their jobs are more likely to have negative attitudes towards clients. While varied implicit and explicit factors are linked to health workers' job satisfaction, the most notable and consistent factors are related to health workers' satisfaction with their remuneration $(18,19)$.
Population density has long been linked to health service access. Health facilities located in highly populated areas are more likely to have more people access their services than health facilities in areas where the catchment population is low (20).

This paper is an exploratory study estimating the impact of PBF on quality of care and the contextual factors mediating the effectiveness of PBF in improving quality of care in Zimbabwe. Our analysis was guided by a conceptual framework for how PBF, as a strategic purchasing tool, influences the behaviors of health providers and other key health system stakeholders towards improved health outcomes (21). The study uses quantitative data from two rounds of household surveys and two rounds of health facility surveys in Zimbabwe, an LMIC that introduced PBF in 2011. Given the paucity of evidence on PBF's effect on health services and health outcomes, this study empirically tests the effect of PBF on quality of care. In addition, the study explores how contextual factors affect PBF's effects on quality of care outcomes in an LMIC context, Zimbabwe, through a quasi-experimental evaluation.

\section{Study context}

According to the World Health Organization (WHO) 2010 country burden of disease profile, at least threequarters of annual deaths in Zimbabwe can be attributed to communicable, maternal, perinatal, and nutritional illness (6). Once a regional beacon of economic and human development, Zimbabwe sank into a decade-long economic crisis in the late 1990s. Zimbabwe's socioeconomic collapse destabilized the pillars of the country's health sector: human resources for health, pharmaceutical and equipment supplies, health care financing, and service delivery. Health indicators and outcomes deteriorated, and Zimbabwe fell behind its sub-Saharan African peers on progress toward Millennium Development Goals (World Bank 2015). Quality of health care declined, as evidenced by several household and facility surveys showing major deficits in the quality of ambulatory and hospital health care services [Zimbabwe Demographic and Health Surveys (ZDHS) 2005 and 2009; a study by the USAID's Maternal and Child Health Integrated Program 2012; and the National Integrated Health Facility Assessment of 2012]. In 2015, Zimbabwe's maternal mortality ratio (MMR) was at 614/100,000 live births and the infant- (IMR) and underfive mortality rates (U5MR) were 45/1,000 live births and 75/1,000 live births respectively (22). Further, Zimbabwe 
has a high rate of neonatal deaths, the majority of which occur in the first 24 hours postpartum because of preterm birth complications, birth asphyxia, and neonatal sepsis. These poor outcomes are in many ways linked to the poor quality of care.

\section{Methods}

In July 2011, the Government of Zimbabwe (GOZ)through the World Bank's Health Sector Development Support Project—rolled out a PBF program to improve the quality and quantity of health services provided by health facilities in selected districts. The PBF project introduced a fee-for-service scheme for the delivery of a package of high-impact $\mathrm{MCH}$ services. The GOZ and the World Bank collected data in 2010/2011 and 2014 (baseline and end line years, respectively) from facilities and households in the surrounding catchment area to monitor health-related outcomes. The intervention is described in more detail in Appendix I.

\section{Selection of PBF intervention and control areas}

Thirty-two districts served as the total study sample for the impact evaluation, comprising $16 \mathrm{PBF}$ pilot districts and 16 comparison districts. These 32 districts were purposively sampled from the population of 64 districts in Zimbabwe and then pair-matched on the basis of observable information described below. The pair-matching process sought to improve the power of inference and provide balance on observable district and facility characteristics. One district in each pair was allocated to the PBF and the other district to the control (business-as-usual) by the MOHCC. The district matching process considered the following characteristics: geographic accessibility-i.e., ruralness and remoteness - type and level of health facilities, average facility catchment population, proportion of staff in position, presence of key staff such as the District Medical/ Health Officer, health services utilization rates for antenatal and postnatal care (PNC) coverage, and institutional delivery and immunization rates for 2008, 2009, and 2010.

For pair-matching of districts, all indicators were combined into one index through principal component analysis; this index was then organized into quintiles. Within each province, two districts from the top (high capacity) and two from the bottom (low capacity) of the index score derived from these measures were selected. Zimbabwe MOHCC leadership then purposively selected one of the two districts in each matched pair to receive the PBF intervention. Thus, the identification strategy for the impact evaluation is a quasi-experimental difference-in-differences (DID) estimator applied within these matched pairs.

In this paper, we aim to objectively (I) estimate the effect of PBF on quality of care; and (II) identify contextual factors that mediate the influence of PBF on quality of care measures.

\section{Study design}

The study used a quasi-experimental research design to evaluate the impact of PBF on utilization of key health services. The study utilized 116 enumeration areas (EA) used in the ZDHS. These EAs were drawn from census files. The study covered rural health centers in intervention and control districts.

The baseline and end line surveys were conducted in both treatment and control health facilities. However, for household surveys, data was not collected during the baseline survey and data from the 2010-2011 ZDHS was used in lieu of a formal, separate sample.

\section{Sampling}

The analysis made use of secondary data obtained from household and health facility datasets. The first dataset contained information on households and health facilities, while the second dataset contained information on health workers. The two datasets were merged to allow for comprehensive analysis on contextual factors.

When matching health facilities to households, two assumptions were made: (I) communities use the health facilities nearest to them (i.e., the "nearest neighbor" assumption); and (II) households are less likely to seek health services in an administrative district different from the one in which they reside. As such, households near district borders were assigned to health facilities within their district.

Pairing of households to health facilities was done at the community level. Appendix II provides the detailed pairing methodology. Communities without location details (i.e., that were not captured at the time of the survey) were excluded from the matching. The final dataset covered 22 districts, i.e., 11 districts as the $\mathrm{PBF}$ group and 11 districts as the control group, across eight provinces. A sample of 1,104 pregnancies were used for the analysis and a total of 55 communities were included in the analysis. 


\section{Dataset}

In this dataset, each row of data represented a woman who had a birth in the two years preceding the survey. Quality of care was measured through recalls by women who had a pregnancy-related outcome over the past two years, health worker interviews focusing on core quality protocols for maternal, newborn, and childcare, and direct observations of specific maternal and newborn clinical care procedures. Participants were asked a series of dichotomous (yes/ no) questions as to whether certain antenatal care (ANC) services were performed during their visit. Six items, from both the women's recall and health facility information, were summed to create a composite score for the number of ANC services performed (see Appendix III for further details on the quality index). The composite score also assessed availability of drugs and equipment necessary for ANC services. The same was done for curative care, institutional deliveries, PNC and extended program on immunization (EPI). The overall quality index was a composite of the above-mentioned quality of care measures.

\section{Data analysis}

Due to the nature and design of the PBF program evaluation, i.e., quasi-experimental, the DID method was used to estimate PBF's effect on quality of care for specified MCH services. A composite quality of care measure (QoC) was constructed by summing the quality measures for the five MCH services, namely ANC, PNC, EPI, delivery, and curative care (refer to Appendix III). The DID method compares the change in quality of care in the PBF group to the change in outcomes in the control group. The method allowed for control of observed and unobserved time invariant characteristics as well as for time-varying factors that exist in both the PBF and control facilities and time varying observables. Changes in quality of care observed among control facilities was considered to reflect the change that would have happened among $\mathrm{RBF}$ facilities had they not implemented PBF. A multivariate regression specification of the DID model was estimated where individual quality of care measures was regressed against a dummy variable indicating whether the facility was receiving under $\mathrm{PBF}$ a pre- or post-indicator, and a series of individual, health facility, and household characteristics. Robust standard errors clustered at the district level were calculated to correct for correlation of the error terms. The models were estimated using Stata version 13 . The analysis was carried out in two stages.

\section{Stage 1: effects of PBF on quality of care}

Health facility data merged with household files informed this analysis. The DID regression model was estimated as following:

$$
\mathrm{QoC}_{\mathrm{ifd}}=\beta_{0}+\beta_{1}(\mathrm{~T})_{\mathrm{f}}+\beta_{2}(\mathrm{PBF})_{\mathrm{d}}+\beta_{3}\left(\mathrm{~T}^{*} \mathrm{PBF}\right)_{\mathrm{fd}}+\varepsilon_{\mathrm{ifd}}
$$

where $i$ is the sample of women who gave birth in the two years prior to the assessment in the facility $d . \mathrm{PBF}_{\text {id }}$ is an indicator showing the treatment status of the facility. $T_{\text {id }}$ represents the time-period under consideration; it takes the value 1 if year is 2014 and 0 if 2010 . The constant $\beta_{0}$ is baseline estimator of mean quality measure in the control facilities and $\beta_{1}$ measures the baseline difference in mean quality between the control and PBF facilities prior to implementation of PBF; $\beta_{2}$ is the difference between the estimated mean quality measurement pre- and post-PBF among the control facilities. The effect of PBF on quality was estimated by $\beta_{3}$, and $\varepsilon_{\mathrm{id}}$ is the error term adjusted for clustering at district level.

To investigate heterogeneity by baseline contextual factors, contextual factors were interacted with treatment to identify salient factors that significantly affected the treatment's effect on quality of care measures. These factors were introduced to determine the most influential factors using the following joint regression specification. We estimated the following model:

$$
\begin{aligned}
& \mathrm{QoC}_{\mathrm{ifd}}=\beta_{0}+\beta_{1}(\mathrm{~T})_{\mathrm{f}}+\beta_{2}(\mathrm{PBF})_{\mathrm{d}}+\beta_{3} \mathrm{~T}^{*} \mathrm{PBF}_{\mathrm{fd}}+\beta_{4} X_{\mathrm{ifd}}+ \\
& \beta_{5} \mathrm{X}_{\mathrm{ifd}}{ }^{*} \mathrm{~T}^{*} \mathrm{PBF}_{\mathrm{fd}}+\varepsilon_{\mathrm{fd}},
\end{aligned}
$$

where the parameter of interest is $\beta_{5}$, which captures whether the impact of PBF differs by pre-specified baseline characteristics.

\section{Stage 2: contextual factors that mediate the influence of PBF on quality of care measures}

Given this evidence, four hypotheses informed development of a list of variables to use for this analysis. We test four different baseline contextual factors. First, we look at whether the PBF effect on quality of care measures is diminished for health facilities located farther from the district city capital (administrative center for the health sector). This could be because facilities incur more costs to achieve minimum quality of care standards relative to those located near the district capital. Second, we look at whether the PBF effect on quality of care measures is stronger for higher levels of baseline health worker 
Table 1 Variables used to identify contextual factors

\begin{tabular}{ll}
\hline Category & \multicolumn{1}{c}{ Factors } \\
\hline $\begin{array}{l}\text { Features of location/ } \\
\text { population, fixed and beyond } \\
\text { control of the health system }\end{array}$ & $\begin{array}{l}\text { Geographic remoteness of a health facility. This was covered in two parts, i.e., the distance between the } \\
\text { household and the health facility and then the distance between health facility and central district health } \\
\text { facility } \\
\text { Facility catchment population } \\
\text { Mean population wealth }\end{array}$ \\
$\begin{array}{l}\text { Features under the control of } \\
\text { the health system }\end{array}$ & $\begin{array}{l}\text { Staffing at baseline (health worker designation, i.e., whether the staff member was a nurse aid, primary } \\
\text { care nurse (PCN), state certified nurse (SNC), registered general nurse (RGN), or midwife) }\end{array}$ \\
$\begin{array}{l}\text { Features directly influenced by } \\
\text { the program }\end{array}$ & \begin{tabular}{l} 
Health worker satisfaction at baseline \\
\hline
\end{tabular}
\end{tabular}

satisfaction, possibly because satisfied health workers are more motivated to provide better quality of care. Third, we look at whether the PBF effect on quality of care measures is stronger for facilities managed by health workers with higher qualifications, possibly because higher qualifications position health workers to adhere to minimum standards of care. Finally, we test whether the PBF effect on quality of care measures is stronger for facilities serving larger catchment areas, possibly because when earning potential is higher, facilities can access more resources to improve the service delivery environment.

To test these hypotheses, variables were classified into three categories, i.e., variables that were: (I) fixed and beyond health facilities' control; (II) under the influence of the health system; and (III) directly influenced by the PBF program (refer to Table 1 below).

This study did not collect any human studies data and used data obtained from existing databases so that ethical approval was waived.

\section{Results}

The original PBF evaluation survey was carried out in 32 districts (16 control and 16 treatment), 145 communities (62 control and $83 \mathrm{PBF}$ ), 2,333 households, and 220 health facilities, and with 524 health workers. Datasets were merged to pair communities to health facilities to households with the objective of measuring and investigating the impact of contextual factors. Ensuring only matched districts were kept in the dataset resulted in a final dataset of 56 facilities (20 control and 36 treatment) in 22 districts (11 treatment and 11 control). Of these 20 were control and 36 were PBF facilities.

Summary of the numbers included and those excluded
Table 2 Summary of Included data components

\begin{tabular}{lcc}
\hline Data level & Original & Used in analysis \\
\hline Districts & 32 & 22 \\
Communities & 145 & 55 \\
Households & 2,333 & 1,104 \\
Health facilities & 220 & 56 \\
Health workers & 524 & 103 \\
\hline
\end{tabular}

for each data component, i.e., households, communities, health facilities, and health workers, is given in Table 2.

Table 3 summarizes the differences between PBF and non-PBF facilities at baseline. Overall, facilities under PBF were more likely to be farther from their district's central health facility $(\mathrm{P}=0.036)$. Control facilities were on average $2.0 \mathrm{~km}$ away from the district capital, while PBF facilities were on average $2.6 \mathrm{~km}$ away. The catchment populations of facilities under PBF and control were no different $(\mathrm{P}=0.506)$. For health workers, almost a quarter of the health workers assessed were either state certified nurses (SCNs) or registered general nurses (RGNs). Fewer than $1 \%$ of facility health workers were only primary school educated; education attainment was similar among health workers from PBF and control health facilities. Years of post-qualification experience and sex distribution were similar for PBF and control facilities. Job satisfaction was higher among health workers in PBF facilities compared to health workers in control facilities $(\mathrm{P}=0.014)$.

A total of 464 households were interviewed (see Table 4 below). The average distance between households and health facilities was similar in the control and PBF communities. Households were on average $11.7 \mathrm{~km}$ away 
Table 3 Facility characteristics and baseline balance

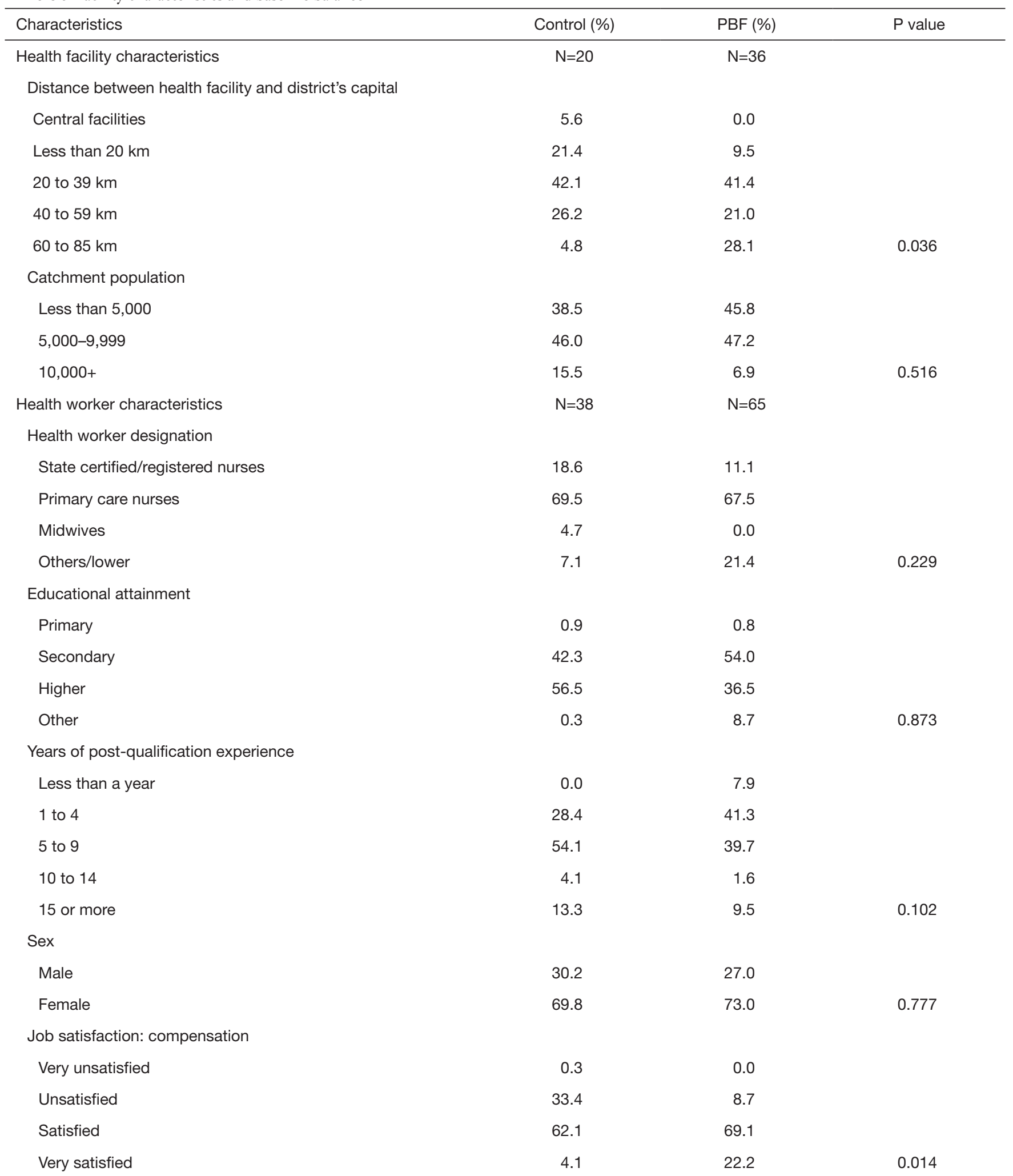

Compensation and overall job satisfaction used as these measures were best available estimates for overall job satisfaction. Clustered at district level. 
Table 4 Effects of PBF on quality of care

\begin{tabular}{|c|c|c|c|c|c|c|}
\hline Quality of care index & \multicolumn{2}{|c|}{ Mean at baseline } & \multicolumn{2}{|c|}{ Mean at end line } & Impact & $P$ value \\
\hline ANC & 0.66 & 0.67 & 0.73 & 0.68 & -0.04 & 0.846 \\
\hline Institutional delivery & 0.71 & 0.74 & 0.72 & 0.67 & 0.01 & $0.08^{*}$ \\
\hline PNC & 0.63 & 0.69 & 0.67 & 0.63 & -0.02 & 0.937 \\
\hline Curative care & 0.75 & 0.74 & 0.72 & 0.69 & 0.13 & 0.171 \\
\hline Overall & 3.56 & 3.65 & 3.67 & 3.50 & 0.63 & 0.552 \\
\hline
\end{tabular}

Sample 1,104 pregnancies. * $\mathrm{P}<0.1$. Impact measured by linear probability model with difference-in-difference specification, including stratification controls. Errors are clustered at the district level.

from health facilities. Education attainment among women seeking services was not different between control and PBF facilities. Seeking of ANC among women differed between the $\mathrm{PBF}$ and control areas.

\section{Effect of PBF on quality of care}

Table 4 investigates the effect of PBF on quality of care. After controlling for baseline imbalances, change in quality of care over time differed among the five services reviewed, i.e., ANC, PNC, institutional delivery, curative care, and EPI. PBF was found to have no effect on quality of care for any services, except institutional deliveries. PBF improved quality of delivery by 0.01 percentage points. After running a DID analysis on composite on quality of care, it was found that, overall, PBF had no effect on quality of care for these maternal, neonatal, and child health services.

Because of the loss of facilities during pairing of health facilities to communities, analysis was carried out on facilities not included in the final analysis to check similarities and differences between included and excluded health facilities and to check for any systematic loss of facilities that would likely result in selection bias. Effect of PBF on quality of health services was calculated for excluded health facilities and compared to results from included health facilities. Analysis on unmerged health facilities was also carried out to find out the impact of PBF on quality of care (refer to Appendix IV: Table S3).

\section{Baseline contextual factors}

Table 5 presents results from investigations on the role of individual contextual factors on their impact of PBF on quality of care. An increase by a kilometer in the distance between health facilities and communities decreased the impact of PBF on quality of care by about $1.21 \%(\mathrm{P}=0.0020)$, while distance between health facility and the district capital center increased impact of PBF on quality of care by less than $1 \%$ for every kilometer. Catchment area population size and mean population wealth also had no impact. Availability of skilled health workers had no impact on PBF effects on quality of care. However, health workers' job satisfaction significantly increased the impact of $\mathrm{PBF}$ on quality of care by $27.7 \%(\mathrm{P}<0.0001)$.

\section{Discussion}

Overall, PBF had no effect on quality of care of the selected $\mathrm{MCH}$ services. PBF did have a marginal effect on provision of quality institutional deliveries. Quality of care for the other four services, i.e., ANC, PNC, curative care, and EPI, were not affected by PBF. This is consistent with several studies that demonstrate that the uptake and quality of services (such as EPI, ANC, and PNC) that require repeated visits are mainly influenced by patients' willingness to follow up on all visits (23).

Study findings pointing to PBF's mixed effects on different quality of care outcomes are consistent with various other studies (5,24-26). As a strategic purchasing tool, PBF should have a clear focus informed by a country's context. Thus, policy makers and program managers must have clear understanding of structural prerequisites and related process quality measures that influence achievement of desired quality outcomes (5). In the case of Zimbabwe's PBF program, policy makers and program planners could be more strategic in selecting the structural and outcome 
Table 5 Influence of contextual factors on PBF effects on quality of care

\begin{tabular}{|c|c|c|c|}
\hline Variables & Impact & $P$ value & $95 \%$ confidence interval \\
\hline Distance between health facilities and communities & -1.21 & $0.0020^{\star \star \star}$ & -1.97 to -0.45 \\
\hline Distance between health facilities and district capital & 0.83 & $<0.0001^{\star \star \star}$ & 0.53 to 1.13 \\
\hline Catchment area population & 2.2 & 0.843 & -21.3 to 25.8 \\
\hline \multicolumn{4}{|l|}{ Features under the control of the health system } \\
\hline Availability of skilled worker & -8.15 & 0.214 & -17.24 to 0.94 \\
\hline \multicolumn{4}{|l|}{ Features directly influenced by the program } \\
\hline Health workers' job satisfaction & 27.66 & $<0.0001^{\star \star \star}$ & 20.11 to 35.22 \\
\hline
\end{tabular}

Sample 1,104 pregnancies. ${ }^{* *}, \mathrm{P}<0.01$. Impact of features of location/population, fixed and beyond control of the health system on quality of care were done using linear regression while the rest were measured by linear probability model with difference-in-difference specification, including stratification controls. Errors are clustered at the district level.

indicators incentivized by the PBF program. The quality checklist used at program inception has several structural quality indicators not directly linked with improving EPI or curative care, which might explain the limited effects of the incentives on improving these outcomes.

The mediating effect of baseline contextual factors on PBF and quality of care outcomes is mixed. The two components of geographical remoteness of health facilities had varied influence on the effect of PBF on quality of care. Although distance between health facilities and households decreased the quality of health services by about 1.2 percentage points ( $95 \%$ CI: $-1.97,-0.45$ ), distance between health facilities and their district capital centers had no impact. PBF's compensation for geographic remoteness, through an added bonus to health facilities located farthest from district capitals, could have played a positive role in influencing health providers to achieve better quality of care. Earlier qualitative studies in Zimbabwe found that the size of the PBF incentive plays a positive role in motivating health providers (27).

Household wealth did not have any impact on PBF's effect on quality. This contradicts existing evidence that wealth plays a vital role in household health seeking behavior. In 2014 Matovu et al. found that in Uganda, both indirect and direct costs of seeking health were detrimental to household access to health care (28). Lack of influence of household wealth on effect of PBF on quality of care may point to more deterring household factors, one of them being distance to a health facility. Evidence shows that distance of households to the nearest health center is highly detrimental to access and frequency of clinic attendance to health services, even with the removal of user fees (29-31)

Availability of skilled health staff does not necessarily result in improved quality of health services. This is consistent with findings from Matsuoka et al., 2014, who found that on-the-job training and refresher courses were more useful for improving quality of care than just the implementation of PBF and availability of staff at the health facilities (32).

Levels of health worker satisfaction with their compensation was found to cause the largest change in PBF's effect on quality. Health worker satisfaction with compensation improved PBF's effect on quality of health services by 27.7 percentage points ( $95 \%$ CI: 20.1, 35.2). The role of such a contextual factor-one within policy-maker control-underscores the importance of understanding the role played by those contextual factors influenced by the health system and those influenced by programs.

This study provides evidence that availability of health workers who are satisfied, and hence willing to provide their best skills to improve quality of health services, is central to successful PBF implementation.

\section{Limitations}

The results from unmerged health facilities on effect of PBF on quality of care differ because of baseline imbalances between the two sets of health facilities, i.e., unmerged and merged health facilities. Hence results from this subset of merged health facilities cannot be used to generalize results 
for all facilities under PBF.

\section{Conclusions}

Evaluations of complex health system reform interventions such as PBF must go beyond exploring effects on priority health outcomes. Evidence on the role of contextual factors is equally important in understanding complex health system interventions. This study provides evidence on the extent to which contextual factors mediate PBF's effect on quality of care. Contextual factors relevant to policy makers and the health systems they are seeking to strengthen can be considered during the design of future studies. On the other hand, contextual factors outside the control of policy makers and the health system-such as mean population wealth—must be further studied.

\section{Acknowledgments}

Funding: This study was funded by the World Bank Health Results Innovation Trust Fund.

\section{Footnote}

Provenance and Peer Review: This article was commissioned by the editorial office, Journal of Hospital Management and Health Policy for the series "Incentives and health system efficiency in low- and middle-income countries". The article has undergone external peer review.

Conflicts of Interest: All authors have completed the ICMJE uniform disclosure form (available at http://dx.doi. org/10.21037/jhmhp-20-60). The series "Incentives and health system efficiency in low- and middle-income countries" was commissioned by the editorial office without any funding or sponsorship. WZ served as the unpaid Guest Editor of the series and serves as an unpaid editorial board member of Journal of Hospital Management and Health Policy from August 2019 to July 2021. Dr. RUM reports grants from World Bank, during the conduct of the study. Dr. JF reports grants from The World Bank, during the conduct of the study. The authors have no other conflicts of interest to declare.

Ethical Statement: The authors are accountable for all aspects of the work in ensuring that questions related to the accuracy or integrity of any part of the work are appropriately investigated and resolved. This study did not collect any human studies data and used data obtained from existing databases so that ethical approval was waived.

Open Access Statement: This is an Open Access article distributed in accordance with the Creative Commons Attribution-NonCommercial-NoDerivs 4.0 International License (CC BY-NC-ND 4.0), which permits the noncommercial replication and distribution of the article with the strict proviso that no changes or edits are made and the original work is properly cited (including links to both the formal publication through the relevant DOI and the license). See: https://creativecommons.org/licenses/by-nc-nd/4.0/.

\section{References}

1. Josephson E, Gergen J, Coe M, et al. How do performance-based financing programs measure quality of care? A descriptive analysis of 68 quality checklists from 28 low- and middle-income countries. Health Policy Plan 2017;32:1120-6.

2. Das A, Gopalan SS, Chandramohan D. Effect of pay for performance to improve quality of maternal and child care in low- and middle-income countries: a systematic review. BMC Public Health 2016;16:321

3. Cashin C, Chi YL, Smith PC, et al. Paying for Performance in Health Care. Berkshire: Open University Press; 2014.

4. Fritche GB, Soeters R, Meessen B. The World Bank Group. Washington, DC, USA; 2014. PerformanceBased Financing Toolkit. Open Knowledge Repository. Available online: https://openknowledge.worldbank.org/ handle/10986/17194. Accessed November 30, 2017.

5. Milstein R, Schreyogg J. A Review of Pay-for-Performance Programs in the Inpatient Sector in OECD Countries. Hamburg: Hamburg Center for Health Economics; 2015.

6. The World Health Organization (WHO). Standards for improving quality of maternal and newborn care in health facilities. Available online: http://www.who.int/maternal_ child_adolescent/documents/improving-maternalnewborn-care-quality/en/

7. Duckett S, Daniels S, Kamp M, et al. Pay for Performance in Australia: Queensland's New Clinical Practice Improvement Payment. J Health Serv Res Policy 2008;13:174-7.

8. Musgrove P. Financial and Other Rewards for Good Performance or Results: A Guided Tour of Concepts and Terms and a Short Glossary. The World Bank. May 2011.

9. Gertler P, Giovagnoli P, Martinez S. Rewarding provider performance to enable a healthy start to life: Evidence 
from Argentina's Plan Nacer. 2014.

10. Meessen B, Musango L, Kashala JP, et al. Reviewing institutions of rural health centres: the Performance Initiative in Butare, Rwanda. Trop Med Int Health 2006;11:1303-17.

11. Basinga P, Gertler PJ, Binagwaho A, et al. Effect on maternal and child health services in Rwanda of payment to primary health-care providers for performance: an impact evaluation. Lancet 2011;377:1421-8.

12. Loevinsohn B. Performance-Based Contracting for Health Services in Developing Countries: A Toolkit. Health, Nutrition, and Population Series. Washington, DC: World Bank. 2008.

13. Friedman J, Das A, Mutasa R. Rewarding Provider Performance to Improve Quality and Coverage of Maternal and Child Health Outcomes. Zimbabwe ResultsBased Financing Pilot Program: Evidence to Inform Policy and Management Decisions. June 17, 2016. World Bank.

14. Akachi Y, Tarp F, Kelley E, et al. Measuring quality-of-care in the context of sustainable development goal 3: a call for papers. Bull World Health Organ 2016;94:160-60A.

15. Bonfrer I, Van de Poel E, Van Doorslaer E. The effects of performance incentives on the utilization and quality of maternal and child care in Burundi. Soc Sci Med 2014;123:96-104.

16. Sila SP, Penn-Kekana L, Harris B, et al. Exploring inequalities in access to and use of maternal health services in South Africa. BMC Health Serv Res 2012 12:120.

17. Kitui J, Lewis S, Davey G. Factors influencing place of delivery for women in Kenya: an analysis of the Kenya demographic and health survey, 2008/2009. BMC Pregnancy Childbirth 2013;13:40.

18. Chimhutu V, Lindkvist I, Lange S. When incentives work too well: Locally implemented pay for performance (P4P) and adverse sanctions towards home birth in Tanzania - A qualitative study. BMC Health Serv Res 2014;14:23.

19. Fox S, Witter S, Wylde E, et al. Paying health workers for performance in a fragmented, fragile state: reflections from Katanga Province, Democratic Republic of Congo. Health Policy Plan 2014;29:96-105.

20. Hanlon P, Carlisle S, Hannah M, et al. A perspective on the future public health practitioner. Perspect Public Health 2012;132:235-9.

21. Health Results Innovation Trust Fund. RBF; A Smarter Approach to Delivering More and Better Reproductive, Maternal, Newborn, and Child Health Services. World Bank Report; 2014.

22. Quality Assurance and Quality Improvement Strategy 2016-2020. Ministry of Health and Child Care [MOHCC]
Zimbabwe, 2016.

23. Ashir GM, Doctor HV, Afenyadu GY. Performance based financing and uptake of maternal and child health services in Yobe Sate, Northern Nigeria. Glob J Health Sci 2013;5:34-41.

24. Binyaruka P, Patouillard E, Powell-Jackson T, et al. Effect of Paying for Performance on Utilization, Quality, and User Costs of Health Services in Tanzania: A Controlled Before and After Study. PLoS One 2015;10:e0135013.

25. Shen, GC, Nguyen HTH, Das A, et al. Incentives to change: effects of performance-based financing on health workers in Zambia. Hum Resour Health 2017;15:20.

26. Gergen J, Josephson E, Coe M, et al. Quality of care in performance-based financing: How it is incorporated in 32 programs across 28 countries. Glob Health Sci Pract 2017;5:90-107.

27. Nguyen T, Stuart L, Reddy K. Ownership Concentration and Corporate Performance from a Dynamic Perspective: Does National Governance Quality Matter? International Review of Financial Analysis 2015;41:148-61.

28. Matovu F, Nanyiti A, Rutebemberwa E. Household health care-seeking costs: experiences from a randomized, controlled trial of community-based malaria and pneumonia treatment among under-fives in eastern Uganda. Malar J 2014;13:222.

29. Mwaura LW, Wandibba S, Olungah CO. Effect of distance on access to health services among women with type 2 diabetes in a rural community in Kenya. African Journal of Diabetes Medicine 2017;25:18-20.

30. Kadobera D, Sartorius B, Masanja H, et al. The effect of distance to formal health facility on childhood mortality in rural Tanzania, 2005-2007. Glob Health Action 2012;5:1-9.

31. Kashima S, Suzuki E, Okayasu T, et al. Association between proximity to a health center and early childhood mortality in Madagascar. PLoS One 2012;7:e38370.

32. Matsuoka S, Obara H, Nagai M, et al. Performance-based financing with GAVI health system strengthening funding in rural Cambodia: a brief assessment of the impact. Health Policy and Planning 2014;29:456-65.

doi: 10.21037/jhmhp-20-60

Cite this article as: Mutasa RU, Baird S, Takavarasha F, Markus A, Friedman J, Zeng W. Exploratory study estimating the impact of performance-based financing (PBF) on quality of care and on the contextual factors mediating the effectiveness of $\mathrm{PBF}$ in improving quality of care in Zimbabwe. J Hosp Manag Health Policy 2021;5:14. 


\section{Appendix I Study intervention}

\section{Summary description of intervention}

The PBF program offers a quarterly financial reward to health facilities based on their verified delivery of a wellprioritized, high-impact package of $16 \mathrm{MCH}$ services at rural health center (RHC) level, and five referral services at secondary hospital level (Tables S1 and S2).

Health facility teams can use $25 \%$ of the PBF payment for staff incentives and $75 \%$ to improve delivery and quality of health services. Incentives are divided among individuals based on a formula that gives more weight to health workers working in higher positions, having longer tenure, and assuming more direct responsibility for the incentivized services.
An internal verification process is undertaken by Cordaid, an international NGO that audits self-reported quantity data by health providers. Quarterly quality audits by the District Health Executive (DHE) and Provincial Health Executives (PHEs) verify the quality of services provided based on a standard protocol. Communitybased organizations (CBOs) undertake client tracer and satisfaction surveys using a predefined instrument. Client feedback and assessment of services received constitutes $20 \%$ of the overall quality score received by a health provider in a given quarter. An external verification undertaken by the University of Zimbabwe Department of Community Medicine independently audits the reported data. At the district level, hospitals receive performancebased contracts to improve the quality of emergency

Table S1 PBF services and subsidies in rural health centers (primary level)

\begin{tabular}{|c|c|c|c|}
\hline Indicator number & Indicator & Current price (after Sept. 2013), \$ & Price before Sept. 2013, \$ \\
\hline 1 & OPD new consultations ${ }^{1}$ & $0.10 / 0.05$ & 0.16 \\
\hline 2 & 1st ANC Visit during first 16 weeks $^{2}$ & 3.00 & 3.00 \\
\hline 3 & ANC 4+ visits completed & 3.00 & 3.00 \\
\hline 4 & HIV VCT in ANC & 1.00 & 2.00 \\
\hline 5 & ARVs to HIV+ pregn. Women (PMTCT) & 2.50 & 2.00 \\
\hline 6 & Tetanus TT2+ & 0.45 & 0.45 \\
\hline 7 & Syphilis RPR test & 0.45 & 0.45 \\
\hline 8 & IPT (×2 doses) & 0.45 & 0.45 \\
\hline 9 & Normal deliveries & 12.50 & 12.50 \\
\hline 10 & High risk perinatal referrals & 3.00 & 3.00 \\
\hline 11 & PN visits 2 or more & 4.50 & 3.00 \\
\hline 12.a & Family planning, short term methods & 1.00 & 2.50 \\
\hline 12.b & Family planning, long term methods & 5.00 & 50.00 \\
\hline 13 & Pri. course completed, immunization & 3.50 & 3.50 \\
\hline 14 & Vit. A supplementation & 0.18 & 0.18 \\
\hline 15 & Growth monitoring, children $<5$ yrs & 0.18 & 0.18 \\
\hline 16 & $\begin{array}{l}\text { Acute Malnutrition cured \& discharged } \\
\text { children }<5 \mathrm{yrs}^{3}\end{array}$ & Moved to sec level & 3.00 \\
\hline
\end{tabular}

1, $\$ 0.05$ for peri urban/high volume; $\$ 0.10$ for other facilities. ${ }^{2}$, indicator added after the PBF technical review. ${ }^{3}$, indicator added after the PBF technical review.

TableS2 PBF services and subsidies in district hospitals

\begin{tabular}{|c|c|c|c|}
\hline Indicator number & Indicator & Current price (after Sept, 2013), \$ & Price before Sept, 2013, \$ \\
\hline 1 & Normal deliveries $^{1}$ & $12.50 / 25$ & 25 \\
\hline 2 & Deliveries with complications & 50 & 80 \\
\hline 3 & Caesarean sections & 140 & 140 \\
\hline 4 & Family planning tubal ligations & 30 & 30 \\
\hline 5 & High-risk per-natal referrals & 3 & 3 \\
\hline 6 & $\begin{array}{l}\text { Acute malnutrition cured \& discharged } \\
\text { children }<5 \mathrm{yrs}^{2}\end{array}$ & 3 & \\
\hline
\end{tabular}

\footnotetext{
${ }^{1}$, normal deliveries are not supposed to be done at a hospital except for refereed complicated deliveries. For hybrid hospitals, normal deliveries are paid $\$ 12.50$ for walk in and $\$ 25.00$ for referred cases. ${ }^{2}$, indicator added after the PBF technical review.
} 
obstetric care and district health management teams are contracted to strengthen quality of supervision. Remote facilities receive higher payments for the delivery of the package of services.

Main project components include: (I) performance-based contracts with health facilities in urban and rural areas; (II) management and capacity building in PBF; (III) monitoring and documentation; and (IV) vouchers for maternal and neonatal services in low-income urban communities.

The formula below shows how the PBF bonus is calculated for the facilities:

$$
P=(1+Q)\left\{\sum_{i=1}^{n} a_{i} b_{i}+R\right\}
$$

where $\mathrm{P}=\mathrm{PBF}$ payment; $\mathrm{Q}=$ quality score; $a_{i}=$ unit price for indicator $I ; b_{i}=$ quantity achieved for indicator $i$; $\mathrm{R}=$ remoteness bonus. Until June 2013, Q was simply the raw score on the quality index. From September 2013, Q is $0-25 \%$, depending on the facility's score on the quality index.

In its regulatory role, the DHE monitors the performance of the health facilities (HFs), which are responsible for direct health care service delivery to communities. The DHE provides feedback and supportive supervision to HFs to enhance their skills and improve their performance. The Health Center Committee: (I) assists the HFs to manage and mobilize locally available resources from communities within an HF's catchment area; and (II) helps ensure the community has a platform to voice their input and perspectives on the project. CBOs are tasked with conducting quality and patient satisfaction surveys.

\section{Appendix II Methodology for matching health facilities and communities}

This brief paper outlines the methodology of the geographic match made between communities and health facilities (HFs) in the Zimbabwe PBF program. It explains the algorithm and its underlying assumptions and concludes with a brief explanation of the resulting dataset.

\section{The data}

The World Bank conducted a Results-Based Financing (i.e., PBF) program in Zimbabwe during 2010/2011 and 2014 (baseline and end line years). These surveys went out to treatment health facilities and nearby households, selected control districts and their respective health facilities, and households in catchment areas. No household data was collected at baseline, so the Demographic Health Survey for Zimbabwe was used in lieu of a formal, separate sample.

\section{Matching methodology}

During data cleaning, all communities without geographical data were excluded from the analysis. The algorithm then calculated the distance between each community and each health facility. Every community and health facility pair within 10 kilometers $(\mathrm{km})$ of each other received an indicator and were removed to a separate dataset. The procedure was then repeated with a radius of $20 \mathrm{~km}$, this time deleting all instances of communities and health facilities that had at least one match in the $10 \mathrm{~km}$ search before determining which communities/health facilities were within $20 \mathrm{~km}$ of each other. Matches at the $20 \mathrm{~km}$ radial level were then appended to the $10 \mathrm{~km}$ dataset. These two steps were repeated once more for a $30 \mathrm{~km}$ radius, again eliminating all community/health facility pairs that matched in either the $10 / 20 \mathrm{~km}$ search and appending to the $10 / 20 \mathrm{~km}$ dataset, and stopped after this point.

The resulting matched dataset attempted to pair communities to their nearest health facilities, on the assumption that they will most likely frequent the health facilities closest to them. This procedure did not pair households with health facilities across district lines. The particular circumstances in Zimbabwe suggest that households will not travel to health facilities in another district, so matching them would be improper.

The reasoning behind the radial search procedure tried to balance three principles simultaneously. They were, in order of priority:

(I) Find communities to pair with as many health facilities in our dataset as possible;

(II) Match communities to their closest health facilities (avoid Type I error); and

(III) Since the sample does not include every single health facility in the country, ensure we do not match communities to health facilities when they would actually go to a different, non-sampled health facility that is closer (avoid Type II error).

Type I errors would occur if we say communities do not match to a health facility when they, in fact, do. This would likely happen if we do not match a community to a "nearby" health facility, based on some measure of geographic distance. No communities more than $30 \mathrm{~km}$ away from a health facility will ever be matched, and the radial search brings some extra rigor to the nearest health facility principle. Type II errors occur if we say a community matches with a health facility when it in fact does not. We are fairly confident that communities within $10 \mathrm{~km}$ of a health facility would use that health facility, so the first radial search should be fairly error-free. The second $20 \mathrm{~km}$ search only searches for health facilities that do not have any communities yet paired with them. This searches over a list of communities that have not been paired up yet either. A similar procedure occurs with the $30 \mathrm{~km}$ search. The algorithm stops after $30 \mathrm{~km}$ because we assume that no community will travel more than $30 \mathrm{~km}$ to a health facility, at least for the services this survey addresses.

\section{Results}

These cleaning and matching procedures produced a dataset with 84 health facilities paired with 91 community centers. There were 1,740 total observations, where an observation represented most recent births to women in households within $10 / 20 / 30 \mathrm{~km}$ of a paired health facility. 
and

(ion

and

at ans

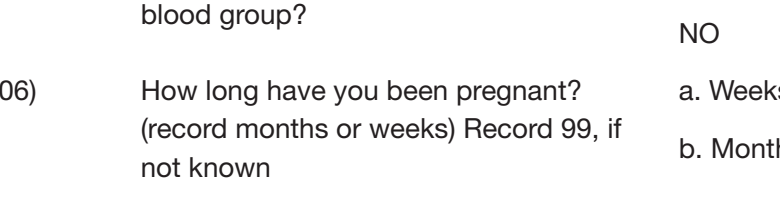

-

(1)

s.t.

197

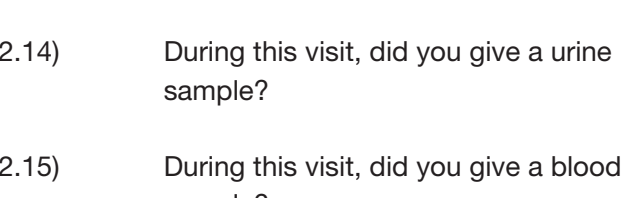

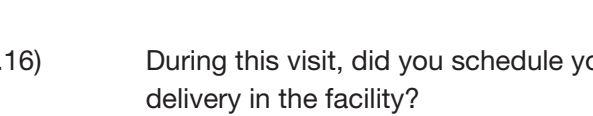

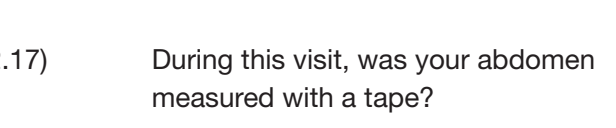

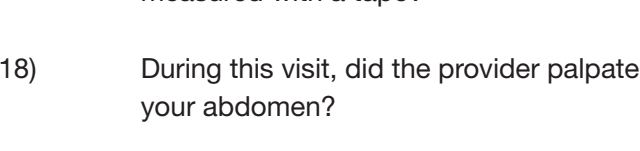

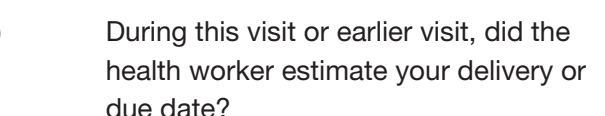

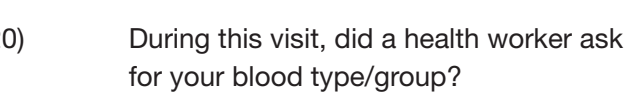

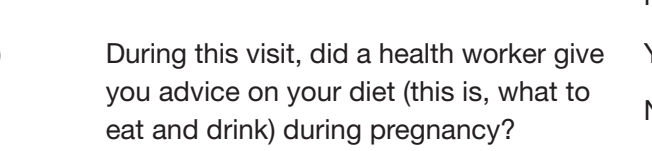

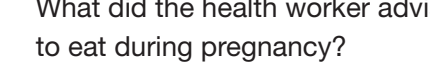

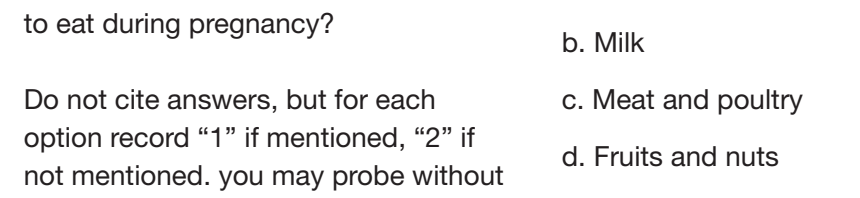

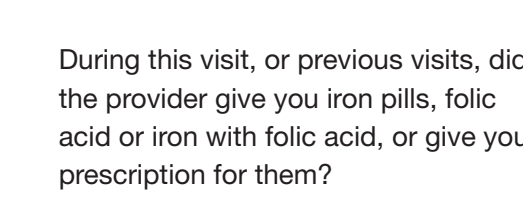

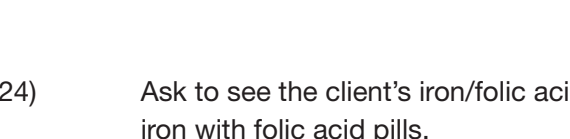

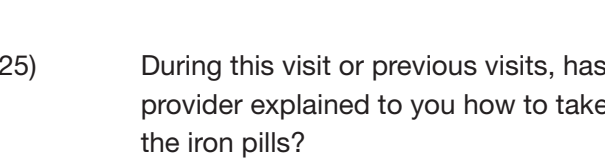

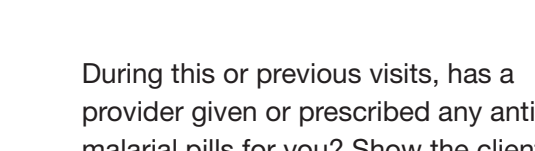

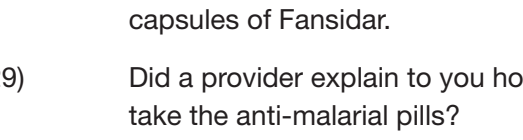

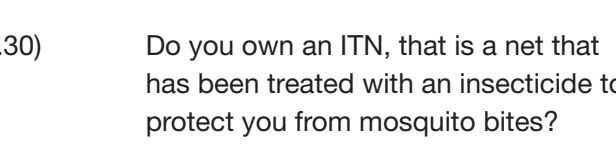

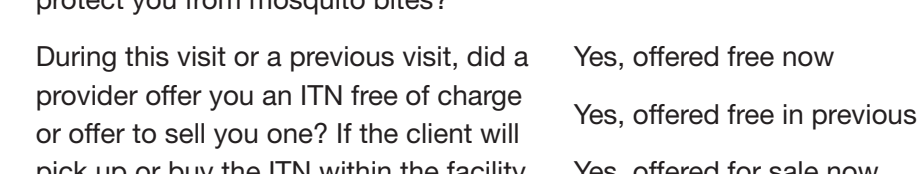

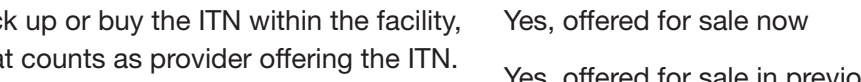

32)

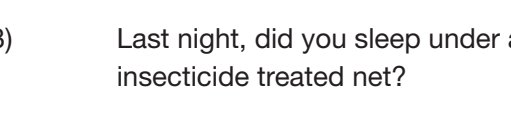

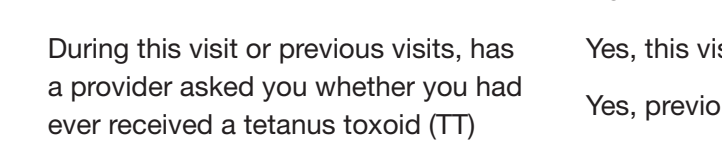

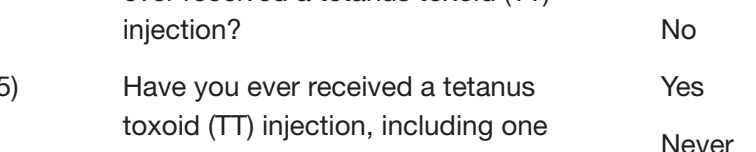

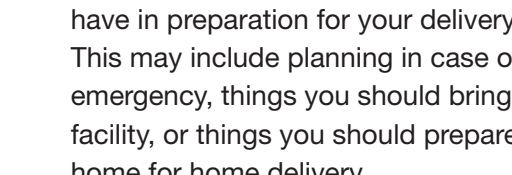

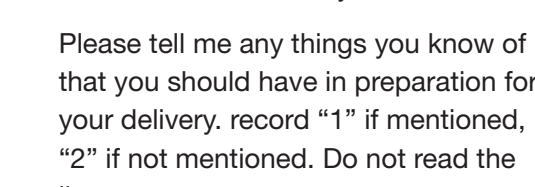

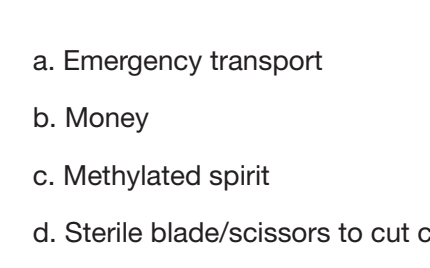

2.39)

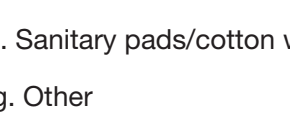

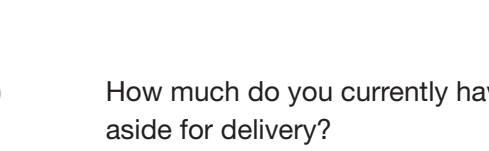

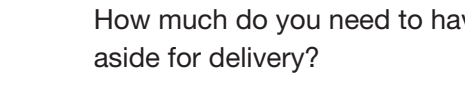

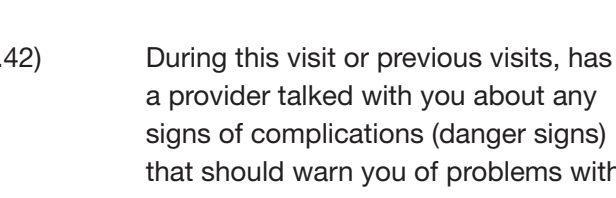

2.is)

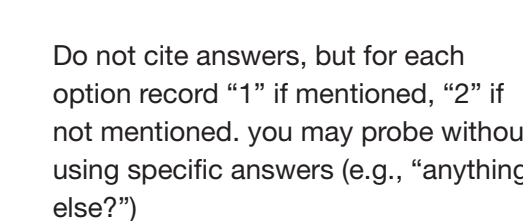

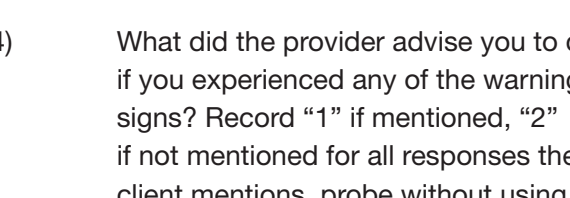

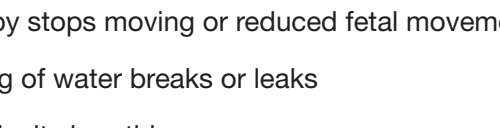

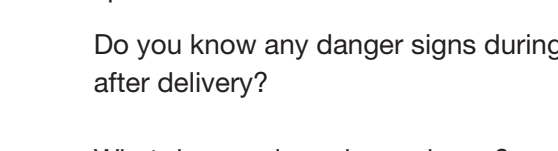

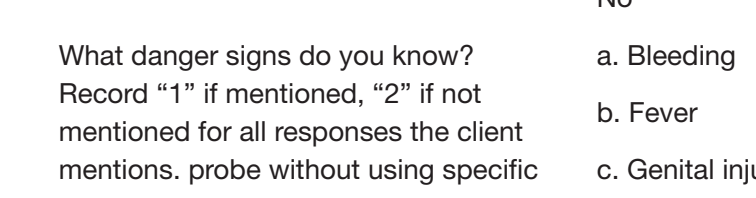

ant

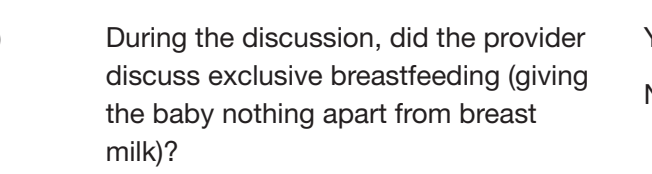

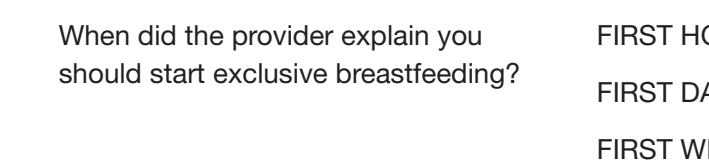

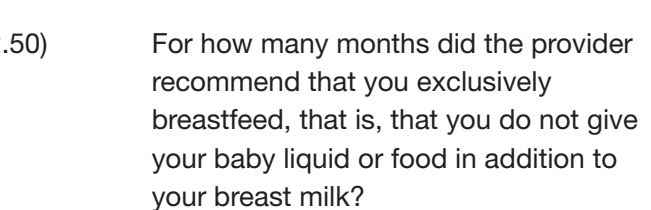

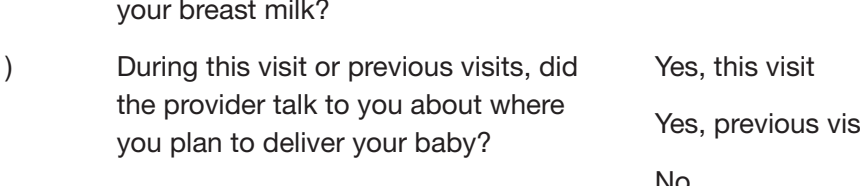

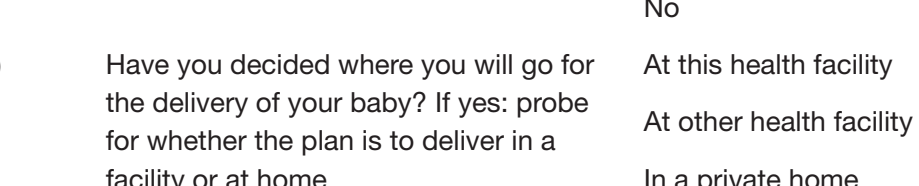

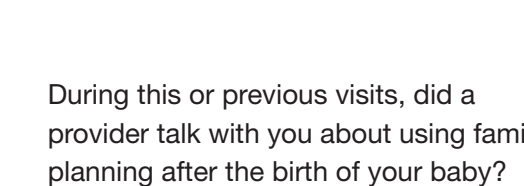

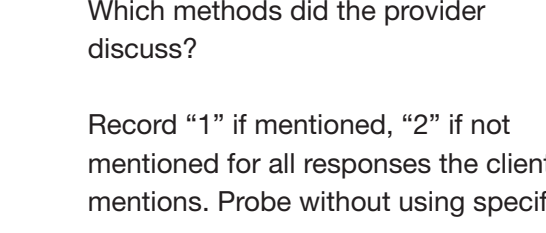

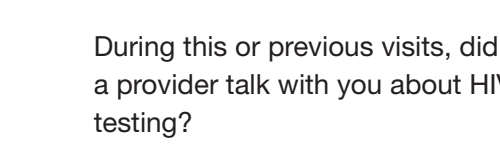

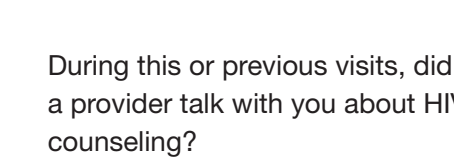

$: \begin{aligned} & (200) \\ & (206)\end{aligned}$

1
2
2
3

3
3
98
01
01
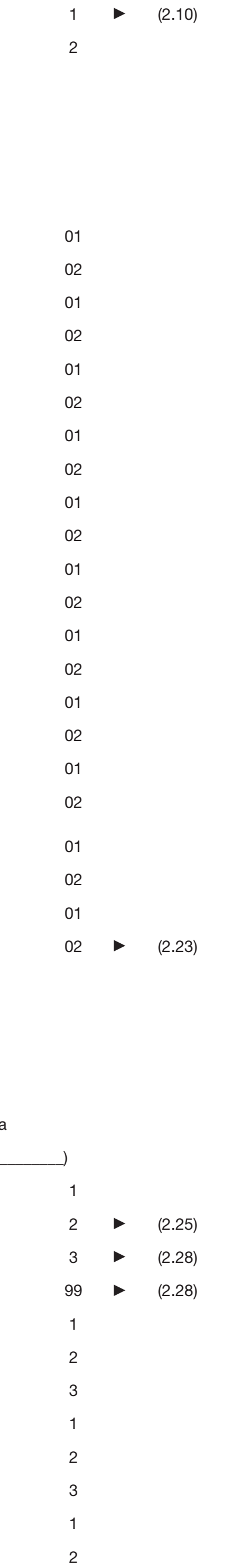


\section{Appendix IV Results}

Table S3 Impact of PBF on quality of care, all health facilities

\begin{tabular}{|c|c|c|c|c|c|c|}
\hline Quality of care index & \multicolumn{2}{|c|}{ Mean at baseline } & \multicolumn{2}{|c|}{ Mean at end line } & Impact (\%) & $P$ value \\
\hline ANC & 0.68 & 0.67 & 0.74 & 0.68 & 5.6 & 0.105 \\
\hline Institutional delivery & 0.74 & 0.75 & 0.74 & 0.69 & 5.6 & 0.185 \\
\hline PNC & 0.67 & 0.66 & 0.61 & 0.68 & 6.3 & 0.213 \\
\hline Curative care & 0.77 & 0.75 & 0.73 & 0.71 & 0.3 & 0.936 \\
\hline Overall & 3.56 & 3.65 & 3.67 & 3.5 & 18.7 & 0.334 \\
\hline
\end{tabular}

Clustered at district level. 